\title{
Orphans, HIVE and HAND: Who are the watch-keepers?
}

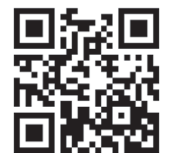

Since 2004, substantial numbers of South African (SA) children have benefited from antiretroviral treatment. Untreated children are at risk of central nervous system (CNS) sequelae, with prevalence rates of $20-60 \%{ }^{[1,2]} \mathrm{HIV}-1$ invades the developing CNS earlier and with greater severity than in adults, resulting in the condition known as HIV encephalopathy (HIVE). ${ }^{[1]}$ In addition, patients on highly active antiretroviral therapy (HAART) may remain vulnerable to the effects of HIV on the brain, because the CNS may be a reservoir for persistent viral replication. ${ }^{[3]}$ The concept of a 'milder' form of neurocognitive disturbance in HIV-infected children, akin to the adult condition of HAND (HIV-associated neurocognitive disorder), is recognised but has yet to be defined. ${ }^{[4]}$

This 'milder' condition of HAND may have significant effects in functional terms on a child's learning potential. Furthermore, early severe deprivation is often associated with neurocognitive delay and/ or cognitive impairment. ${ }^{[5,6]}$ Facilitating optimal development of 'heart', mind and body is a priority among professionals caring for sick children.

In SA, children with developmental quotients (DQs) of $\geq 65$ attend mainstream schools. Those with DQs between 35 and 50 may receive education at training centres. Children in the grey area with DQs of 51 - 64 may go onto a waiting list for a special-needs school. However, the trend now is for inclusive education, and the reality is that such learners remain in mainstream schooling with minimal remedial support. Two short case scenarios and a letter from an educator highlight the limitations of this system in the context of children living with HIV.

A, aged 10 years. A spent the early part of his life in St Joseph's Home in Cape Town as an orphan, because no family member could be traced. When he was 1 year old, HIVE was diagnosed and he was enrolled on HAART. He had a mastoidectomy which has left him disfigured. When he was 25 months old, a developmental assessment showed that his gross motor development was at the level of 11 months, his fine motor development at 18 months, his language at 9 months and his personal/social development at $9-12$ months. Repeated tests showed a similar pattern. It was recommended that he attend a LSEN (learner with special education needs) school, but we were informed that when he went for assessment, his 'home' mother at the orphanage was told he was too high-functioning to attend. He was therefore enrolled in a mainstream school in grade R in 2009 and proceeded to grade 1 in 2011 . The attending developmental paediatrician wrote to the education district office in 2011 and recommended consideration for transfer to an LSEN school. This did not happen, and he repeated grade 1 in 2012. Apparently he receives ongoing teacher support after school in a class of 8 children. His DQ is 75 , with severe weaknesses in his verbal score and with abstract tasks. Each year, his report shows outcome scores of 1 ('not achieved') despite which he gets promoted to the next grade. He is now 10 years old, cannot read and has rudimentary writing and numeracy skills. The health professionals and his caregiver are all concerned regarding his future. He appears to be happy and he gets on well with the other children at the orphanage, 
but what does the future hold for this child? What can he dream about achieving, and how can we help him to set achievable goals?

B, aged 12 years. B was abandoned by her mother and spent her early years in Nazareth House, Cape Town. HIVE was diagnosed and HAART commenced. Placement at a children's home was secured. Her motor milestones were delayed and she only walked independently at 2 years, 7 months. She apparently repeated grade 1 three times and grade 2 twice. She underwent cognitive testing in 2011, which showed that her general intellectual functioning was borderline, motor co-ordination average, processing speed borderline, attention profoundly impaired, working memory average, visual spatial ability borderline, language low average, verbal memory low average, visual memory borderline, and executive functioning low average. Behaviour problems necessitated psychiatric referral. She continues to struggle at school, and her caregiver and attending health professionals are extremely concerned. She has responded well to antiretrovirals (ARVs) and is virologically suppressed, but what chance does she have of living a dignified and fulfilling life when she cannot read and struggles with numeracy?

The two children described represent the tip of the iceberg. In our clinics we have at least another 150 about whom we are concerned. What about children in the rural areas? Such children will leave school at the age of 16 years and in all likelihood will never have the satisfaction of being employed. Educators, as reflected in the letter below from a caring teacher, are turning to health professionals for education plans.

'T've got this little boy called ----. He came to my attention this year. He is doing grade 2 for the first time. He is not coping at all. He cannot read. He only writes when we copy from the chalk-board. He cannot listen to the instructions and answer correct questions. He just copy [sic] the questions again. He repeated grade 1 and progresses to the next grade. Our policy stated that child cannot stays [sic] in same grade for more than 2 years. Because of that policy he is going to be progressed [sic] to the next grade what [sic] is grade 3 .'

This editorial seeks to create an awareness of this tragic problem. How do we find ways of combining health and educational resources to educate and maximise the potential of children living with HIV? Roll-out of ARVs has helped, but these children still have a long and bumpy road to navigate. Their current circumstances fall far short of the realisation of their constitutional rights.

\section{Kathie Walker}

Medical Officer, Neurology and Cardiology, Red Cross War Memorial Children's Hospital, Cape Town, South Africa, and G26 HIV/AIDS Service, Groote Schuur Hospital, Cape Town buley@iafrica.com

\section{Mandy Inglis}

Medical Officer, G26 HIV/AIDS Service, Groote Schuur Hospital, Cape Town, South Africa

\section{Gwen Norton \\ Rebecca Sher \\ Dayle Zieff}

Medical Officers, G26 HIV/AIDS Service, Groote Schuur Hospital, Cape Town, South Africa, Crossroads HIV/AIDS Service, Cape Town, and Mitchell's Plain HIV/AIDS Service, Cape Town

\section{Taryn McCann}

Clinical Psychologist, HIV/TB Specialised Health Department, City of Cape Town, South Africa

\section{Paul Roux}

Director, G26 HIV/AIDS Service, Groote Schuur Hospital, Cape Town, South Africa

1. Van Rie A, Harrington PR, Dow A, Robertson K. Neurologic and neurodevelopmental manifestation of pediatric HIV/AIDS: A global perspective. Eur J Paediatr Neurol 2007;11(1):1-9. [http://dx.doi. org/10.1016/j.ejpn.2006.10.006]

org/10.1016/j.ejpn.2006.10.006]
2. Lobato MN, Caldwell MB, Ng P, Oxtoby MJ. Encephalopathy in children with perinatally acquired human immunodeficiency virus infection. Pediatric Spectrum of Disease Clinical Consortium. J Pediatr 1995;126(5):710-715. [http://dx.doi.org/10.1016/S0022-3476(95)70397-7]

3. Sonza S, Crowe S. Reservoirs for HIV infection and their persistence in the face of undetectable viral load. AIDS Patient Care STDS 2001;15(10):511-518. [http://dx.doi.
und org/10.1089/108729101753205676

4. Martin SC, Wolters PM, Toledo-Tamula MA, et al. Cognitive functioning in school-aged Martin SC, Wolters PM, Toledo-Tamula MA, et al. Cognitive functioning in school-aged
children with vertically acquired HIV infection being treated with highly active antiretroviral children with vertically acquired HIV infection being treated with highly active antiretroviral
therapy (HAART). Dev Neuropsychol 2006;30(2):633-657. [http://dx.doi.org/10.1207/ s15326942dn3002_1]

5. Rutter ML, Kreppner JM, O'Connor TG. English, Romanian Adoptees Study Team. Specificity 5. Rutter ML, Kreppner JM, O'Connor TG. English, Romanian Adoptees Study Team. Specificity
and heterogeneity in children's responses to profound institutional privation. Br J Psychiatry and heterogeneity in children's responses to profound
2001;179(2):97-103. [http://dx.doi.org/10.1192/bjp.179.2.97]

6. Behen ME, Helder E, Rothermel R, et al. Incidence of specific absolute neurocognitive impairment in globally intact children with histories of early severe deprivation. Child Neuropsychol 2008;14(5):453469. [http://dx.doi.org/10.1080/09297040802244136]

S Afr Med J 2014;104(10):678-679. DOI:10.7196/SAMJ.8274 